\title{
. \\ Catalytic Synthesis of Methacrolein via the Condensation of Formaldehyde and Propionaldehyde with L-Proline Intercalated Layered Double Hydroxides
}

\author{
Longxin Ju, Gang Li *(D) and Hongxian Luo
}

check for updates

Citation: Ju, L.; Li, G.; Luo, H. Catalytic Synthesis of Methacrolein via the Condensation of Formaldehyde and Propionaldehyde with L-Proline Intercalated Layered Double Hydroxides. Catalysts 2022, 12, 42. https://doi.org/10.3390/ catal12010042

Received: 13 December 2021 Accepted: 29 December 2021 Published: 31 December 2021

Publisher's Note: MDPI stays neutral with regard to jurisdictional claims in published maps and institutional affiliations.

Copyright: (C) 2021 by the authors. Licensee MDPI, Basel, Switzerland. This article is an open access article distributed under the terms and conditions of the Creative Commons Attribution (CC BY) license (https:// creativecommons.org/licenses/by/ $4.0 /)$.
State Key Laboratory of Fine Chemicals, School of Chemical Engineering, Dalian University of Technology, Dalian 116024, China; julx0208@163.com (L.J.); hongxianluo@163.com (H.L.)

* Correspondence: liganghg@dlut.edu.cn

\begin{abstract}
Aldol condensation reactions are very important $\mathrm{C}-\mathrm{C}$ coupling reactions in organic chemistry. In this study, the catalytic performance of layered double hydroxides (LDHs) in the aldol condensation reaction of formaldehyde (FA) and propionaldehyde (PA) was investigated. The $\mathrm{M}_{\mathrm{x}} \mathrm{Al}-$ LDHs (denoted as re-M $\mathrm{M}_{\mathrm{X}} \mathrm{Al}-\mathrm{LDH} ; \mathrm{M}=\mathrm{Ca}$ and $\mathrm{Mg} ; \mathrm{X}=2-4$ ), as heterogeneous basic catalysts toward the aldol condensation reaction, were prepared via a two-step procedure. The catalyst exhibited a high PA conversion (82.59\%), but the methacrolein (MAL) selectivity was only $36.01 \%$ due to the limitation of the alkali-catalyzed mechanism. On this basis, the direct intercalation of L-proline into LDHs also has been investigated. The influences of several operating conditions, including the temperature, reaction time, and substrate content, on the reaction results were systematically studied, and the optimized reaction conditions were obtained. The optimized $\mathrm{Mg}_{3} \mathrm{Al}$-Pro-LDHs catalyst exhibited a much higher MAL selectivity than those of re-Mg $\mathrm{Al}-\mathrm{LDHs}$.
\end{abstract}

Keywords: layered double hydroxides; L-proline; aldol condensation reaction

\section{Introduction}

Methacrolein (MAL) is an important chemical intermediate for the preparation of methyl methacrylate, thermoplastic monomers, and various fragrances and pharmaceuticals [1-4]. The synthesis of MAL mainly includes the following processes: acetone cyanohydrin process, isobutene direct oxidation process, and formaldehyde (FA) and propionaldehyde (PA) condensation processes. The aldol condensation process using FA and PA can occur under mild conditions with relatively high yield. It can be carried out in two ways, i.e., the direct aldol condensation pathway and the Mannich reaction pathway. The catalysts used in the two reaction pathways are completely different. Direct aldol condensation uses bases such as $\mathrm{NaOH}, \mathrm{KOH}$, or triethylamine as catalysts [5-7]. Although this method has a high conversion of PA, the selectivity of the target product is unsatisfactory. The main side reactions are the self-condensation of the reactants and the Cannizzaro reaction [8]. The Mannich reaction, also known as amine methylation reaction, is one of the important organic reactions and has a good effect of the directional extension of the carbon chain $[9,10]$. The secondary amine/carboxylic acid combination is generally used as a catalyst for this reaction. Lei et al. used different secondary amine compounds to catalyze the reaction of FA and PA to synthesize MAL. The result showed that the catalytic performance of diethylamine is the highest among different secondary amines, and the yield of MAL can reach 94\% [11]. Yu et al. found that L-proline is the optimal catalyst for the Mannich synthesis of MAL among the various amino acid compounds, with a conversion of $97 \%$ and a yield of $94 \%$ [12]. Unfortunately, the industrial application of this catalyst is challenged due to the cost and the subsequent separation. To overcome this issue, L-proline is introduced into different carriers, such as silica materials, metal-organic frameworks (MOFs) and layered double hydroxides (LDHs), and a good yield and a high 
enantioselectivity are obtained in an asymmetric aldol condensation [13-15]. So far, there have been few reports on heterogeneous catalysts for the Mannich reaction of FA and PA to produce MAL.

LDHs are a type of two-dimensional anionic interlayer material, also known as aluminum hydroxide-like compounds. Brucite-like metal cations layers are formed by the octahedral coordination of metal cations and lattice hydroxyl groups. The divalent cations can be replaced by trivalent cations, resulting in a partial positive charge density in the layered architecture. The layers are then maintained by organic or inorganic aninos to balance the positive charge of the metal cations layers, making the LDHs material electrically neutral [16-18]. Amino acids are a common amphoteric compound, and their charged properties can be adjusted by the $\mathrm{pH}$ of the aqueous solution. It is precisely because of the adjustable charging properties of amino acids that make them an ideal choice for intercalation [19-21]. In recent years, based on the concepts of intercalation assembly, many insights on the structure-property correlation have been obtained from the work in the characterization of layered structures, the establishment of structural models, and the functional development of intercalation assemblies [22-26]. In particular, the powerful materials that can be assembled through intercalation have attracted the attention of researchers from all over the world, and they have shown broad application prospects in the field of catalysis [27-29].

In this work, active $\mathrm{M}_{\mathrm{x}} \mathrm{Al}-\mathrm{LDH}$ catalysts with $\mathrm{OH}^{-}$interlayer anions (denoted as re-M $\mathrm{M}_{\mathrm{X}} \mathrm{Al}-\mathrm{LDH} ; \mathrm{M}=\mathrm{Ca}$ and $\mathrm{Mg} ; \mathrm{X}=2-4$ ) were obtained and used in the aldol condensation reaction of FA with PA to produce MAL. Then, based on the amphotericity of amino acids, L-proline was successfully intercalated into the layers by coprecipitation or rehydration and characterized by XRD and FTIR. The catalytic performances of these materials in aldol condensation were also studied.

\section{Results and Discussion}

2.1. $R e-M g x A l-L D H s$ and $R e-C a_{x} A l-L D H s$

2.1.1. Powder X-ray Diffractometry (XRD)

In this paper, re-M $\mathrm{M}_{\mathrm{X}} \mathrm{Al}-\mathrm{LDH}$ were prepared by calcination and subsequently rehydration, and the XRD patterns are shown in Figures 1 and 2. Figure 1A represents the XRD patterns of the prepared $\mathrm{Mg}_{\mathrm{x}} \mathrm{Al}-\mathrm{LDH}$ precursors with various $\mathrm{Mg} / \mathrm{Al}$ ratios. It can be seen that the series of $\mathrm{Mg}_{x} \mathrm{Al}-\mathrm{LDHs}$ had obvious characteristic peaks at $2 \theta$ of $11.20^{\circ}(003)$, $22.56^{\circ}(006), 34.28^{\circ}(009)$, and $60.22^{\circ}(110)$ and the peaks were relatively symmetrical and sharp, which showed that the pure-phase and good-quality precursors were successfully obtained by the co-precipitation method [30-32]. The position of the characteristic peak (003) showed that the interlayer of the $\mathrm{M}_{x} \mathrm{Al}-\mathrm{LDH}$ precursors was mainly $\mathrm{NO}_{3}{ }^{-}$and $\mathrm{CO}_{3}{ }^{2-}$. From the XRD patterns of $\mathrm{Ca}_{\mathrm{x}} \mathrm{Al}-\mathrm{LDH}$, it can be seen that when the ratio of $\mathrm{Ca} / \mathrm{Al}$ was 2 , the characteristic diffraction peak had a strong intensity and there were no other impurity peaks. With the increase of the Ca content, in addition to the decrease in the intensity of the characteristic diffraction peaks of the LDHs phase, the $\mathrm{Ca}(\mathrm{OH})_{2}$ phase diffraction peaks with a lower intensity gradually appeared (centered at $\sim 18.06^{\circ}$ and $\sim 34.26^{\circ}$ ). The excessive $\mathrm{Ca}$ in the sample prepared by the above co-precipitation method did not enter the layers and appeared in the form of the $\mathrm{Ca}(\mathrm{OH})_{2}$ phase, which in turn led to the poor crystallinity of the sample. Because of the large ion radius of $\mathrm{Ca}^{2+}$, it was easy to cause the octahedral structure distortion and increase the sample disorder after entering LDHs layers. Figure 1B represents the XRD patterns of the prepared $\mathrm{Mg}_{\mathrm{x}} \mathrm{Al}-$ composite metal oxides (MMOs) with various $\mathrm{Mg} / \mathrm{Al}$ ratios. After the calcination of $\mathrm{Mg}_{\mathrm{x}} \mathrm{Al}-\mathrm{LDHs}$ precursors, the characteristic diffraction peak of the original LDHs materials disappeared. The peaks at $34.98^{\circ}, 43.01^{\circ}$, and $62.46^{\circ}$ are attributed to the $\mathrm{MgO}$ phase. Since $\mathrm{Al}_{2} \mathrm{O}_{3}$ exists in the amorphous phase, its characteristic diffraction peaks were not observed. The trace amounts of $\mathrm{CaCO}_{3}\left(\sim 29.72^{\circ}\right)$ were found in $\mathrm{Ca}_{x} \mathrm{Al}-\mathrm{MMOs}$, which may be caused by the insufficient calcination or the introduction of $\mathrm{CO}_{2}$ in the synthesis process. Figure $1 \mathrm{C}$ represents the XRD patterns of the re- $\mathrm{Mg}_{x} \mathrm{Al}-\mathrm{LDHs}$. The $\mathrm{Mg}_{\mathrm{x}} \mathrm{Al}-\mathrm{MMO}$ were placed in an 
alkaline solution for structural restoration, and re- $\mathrm{Mg}_{\mathrm{x}} \mathrm{Al}-\mathrm{LDH}$ with the interlayer anions replaced by $\mathrm{OH}^{-}$were obtained, due to the structural memory effect of LDHs materials.

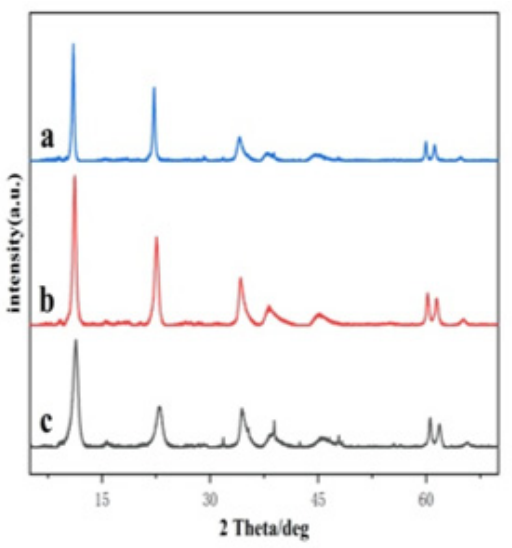

A

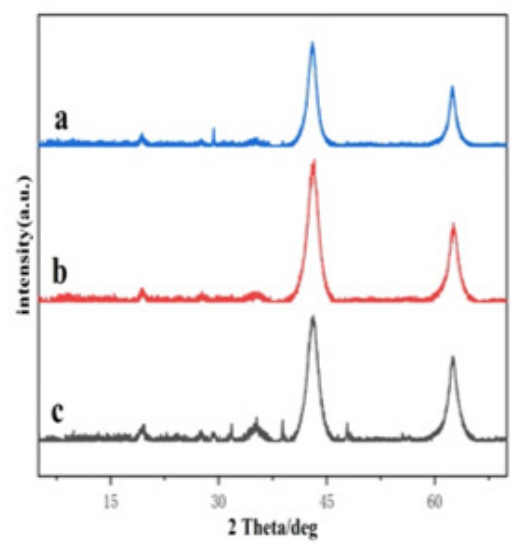

B

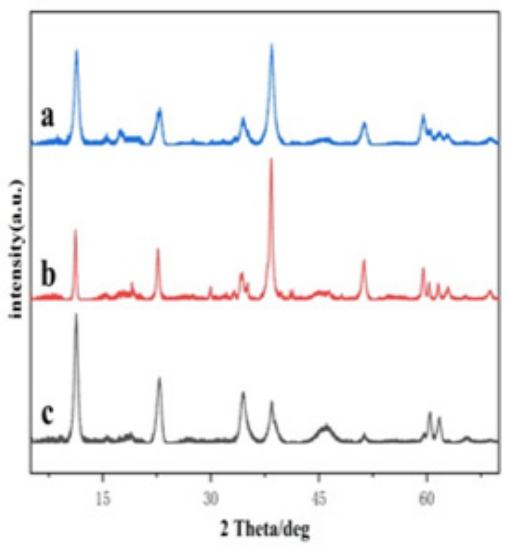

C

Figure 1. XRD patterns of $\mathrm{Mg}_{\mathrm{x}} \mathrm{Al}$-layered double hydroxides (LDHs) (A), $\mathrm{Mg}_{\mathrm{x}} \mathrm{Al}$-composite metal oxides (MMOs) (B), and re-Mg $\mathrm{Al}-\mathrm{LDHs}(\mathbf{C})$, where $\mathrm{a}, \mathrm{b}$, and c represent samples with $\mathrm{Mg} / \mathrm{Al}$ ratios of $2: 1,3: 1$, and 4:1, respectively.

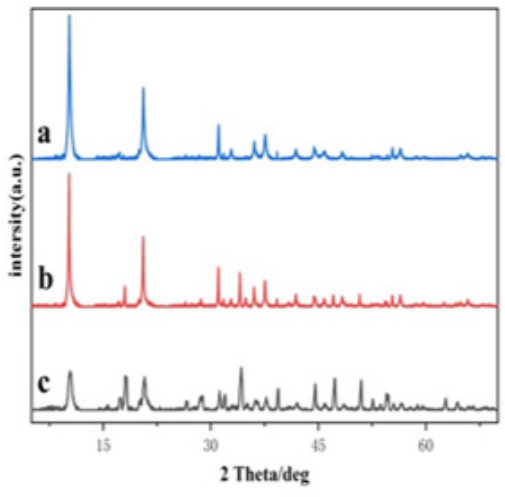

A

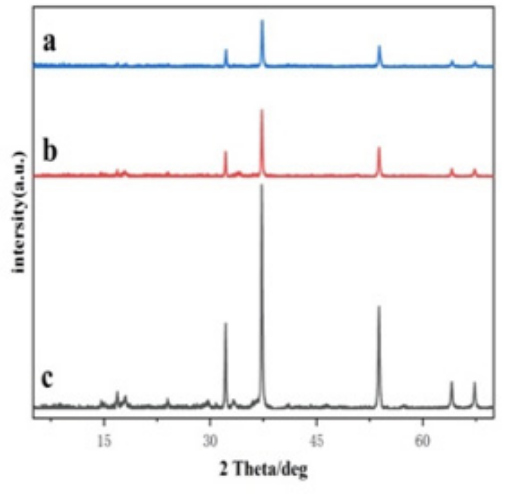

B

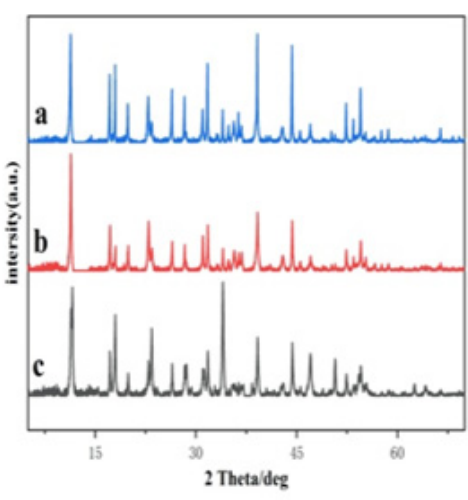

C

Figure 2. XRD patterns of $\mathrm{Ca}_{x} \mathrm{Al}-\mathrm{LDH}(\mathbf{A}), \mathrm{Ca}_{\mathrm{x}} \mathrm{Al}-\mathrm{MMOs}(\mathbf{B})$, and re-Ca $\mathrm{A}$ Al-LDHs (C), where $\mathrm{a}, \mathrm{b}$, and $\mathrm{c}$ represent samples with $\mathrm{Ca} / \mathrm{Al}$ ratios of 2:1, 3:1, and 4:1, respectively.

\subsubsection{Evaluation of the Catalytic Performance}

It can be seen from Table 1 that the solid base catalysts (re-M $\mathrm{Ml}-\mathrm{LDHs}$ ) with $\mathrm{OH}^{-}$ interlayer anions prepared through the process of calcination and subsequently rehydration showed high alkali catalytic activity in the aldol condensation of FA and PA. The effects of different metals and ratios of re- $\mathrm{M}_{\mathrm{x}} \mathrm{Al}-\mathrm{LDHs}$ on aldol condensation were investigated. After the calcination and rehydration of $\mathrm{Mg}_{\mathrm{x}} \mathrm{Al}-\mathrm{LDH}$ precursors, the layered structure was replaced with $\mathrm{OH}^{-}$as an interlayer anion. The obtained re-M $\mathrm{Al}-\mathrm{LDHs}$ sample introduced a large number of $\mathrm{OH}^{-}$anionic basic groups between the layers, which was likely to increase the number of BrØnsted basic sites. Moreover, the disorder degree of the sample structure also increased significantly via a two-step procedure, and its relatively incomplete crystal form (surface defect) led to a fuller exposure of BrØnsted basic sites on the surface. For the calcium-based LDHs catalyst, the conversion of PA and the selectivity of MAL increased gradually with the increase of the $\mathrm{Ca} / \mathrm{Al}$ ratio. For the magnesium-based LDHs catalyst, the conversion of PA and the selectivity of MAL increased first and then decreased with the increase of the $\mathrm{Mg} / \mathrm{Al}$ ratio. The magnesium-based catalyst re- $\mathrm{Mg}_{3} \mathrm{Al}-$ LDHs achieved the optimal catalytic performance in the aldol condensation process (PA conversion: $82.59 \%$; MAL selectivity: 36.01\%). 
Table 1. Results of the aldol condensation reaction with re-M $\mathrm{M} A-\mathrm{LDH}$ catalysts.

\begin{tabular}{ccc}
\hline Catalyst & PA Conversion (\%) & MAL Selectivity (\%) \\
\hline re-Ca ${ }_{2}$ Al-LDHs & 73.61 & 17.93 \\
re-Ca ${ }_{3}$ Al-LDHs & 79.30 & 18.22 \\
re-Ca 4 Al-LDHs & 84.56 & 24.85 \\
re-Mg2Al-LDHs & 80.18 & 21.25 \\
re-Mg3Al-LDHs & 82.59 & 36.01 \\
re-Mg4Al-LDHs & 43.95 & 22.31 \\
\hline
\end{tabular}

Reaction conditions: $0.2 \mathrm{~g}$ catalyst; $15 \mathrm{~mL}$ dimethyl sulfoxide (DMSO); $3.8 \mathrm{~mL}$ formaldehyde (FA); $3.7 \mathrm{~mL}$ propionaldehyde (PA); $60^{\circ} \mathrm{C} ; 4 \mathrm{~h}$.

The product distribution using re-Mg $\mathrm{Al}_{\mathrm{A}} \mathrm{ALDHs}$ is shown in Figure 3. Apart from the cross-condensation of FA and PA to produce MAL, other possible reactions in this system included the self-condensation of PA (2-methyl-2-pentenal (MP)), the isomerization of $\beta$-hydroxyaldehyde (cis-2-butene-1,4-diol (BED)), and the Cannizzaro reaction (1,1,1Tris(hydroxymethyl)ethane (TME)). All the reactions can be carried out under the condition of the base catalysis. After changing the metal ion and ratio of the LDHs material, the selectivity of MAL was still not satisfactory. For this defect, we further intercalated Lproline, which had a high selectivity for the cross-condensation reaction into LDHs.

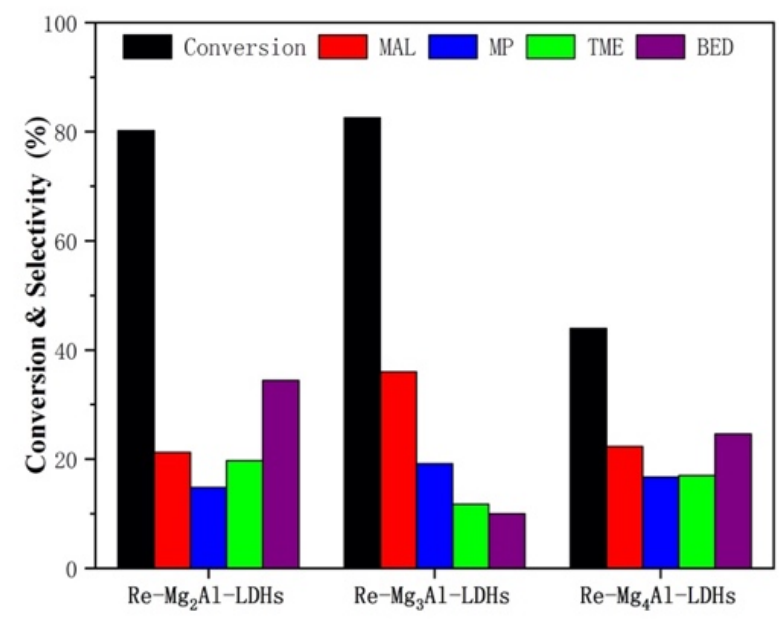

Figure 3. Results of the aldol condensation reaction with re-Mgx $\mathrm{Al}-\mathrm{LDH}$ catalysts.

\section{2. $\mathrm{Re}_{\mathrm{Mg}} \mathrm{Ml} \mathrm{Al}$-Pro-LDHs and $\mathrm{Mg}_{3} \mathrm{Al}-\mathrm{Pro}-\mathrm{LDHs}$}

\subsubsection{XRD}

Re- $\mathrm{Mg}_{3} \mathrm{Al}-\mathrm{Pro}-\mathrm{LDH}$ and $\mathrm{Mg}_{3} \mathrm{Al}-\mathrm{Pro}-\mathrm{LDH}$ were prepared by the rehydration and co-precipitation method, and the XRD patterns are shown in Figure 4. For the $\mathrm{Mg}_{3} \mathrm{Al}-\mathrm{LDHs}$ sample, the main characteristic diffraction peaks appeared at $11.20^{\circ}(003), 22.56^{\circ}$ (006), $34.28^{\circ}$ (009), and $60.22^{\circ}$ (110). The re-Mg $\mathrm{Mg}_{3} \mathrm{Al}-\mathrm{Pro}-\mathrm{LDHs}$ and $\mathrm{Mg}_{3} \mathrm{Al}-\mathrm{Pro}-\mathrm{LDHs}$ showed the similar diffraction peaks, which indicated that the L-proline intercalation by both methods did not affect the original layered structure. According to Bragg's law, the corresponding crystalline spacing can be obtained. For example, the crystalline spacing of the (003) peak in $\mathrm{Mg}_{3} \mathrm{Al}-\mathrm{LDHs}$ was $0.78 \mathrm{~nm}$. After L-proline intercalation, the characteristic peaks (003) of re- $\mathrm{Mg}_{3} \mathrm{Al}-\mathrm{Pro}-\mathrm{LDHs}$ and $\mathrm{Mg}_{3} \mathrm{Al}-\mathrm{Pro}-\mathrm{LDHs}$ shifted to a lower $2 \theta\left(10.20^{\circ} / 9.80^{\circ}\right)$, and the crystalline spacings increased to $0.86 \mathrm{~nm}$ and $0.90 \mathrm{~nm}$, respectively. This is consistent with the literature reports of L-proline intercalation materials, and it can also prove that the Lproline molecules were successfully intercalated into the interlayer of LDHs materials [33,34]. 


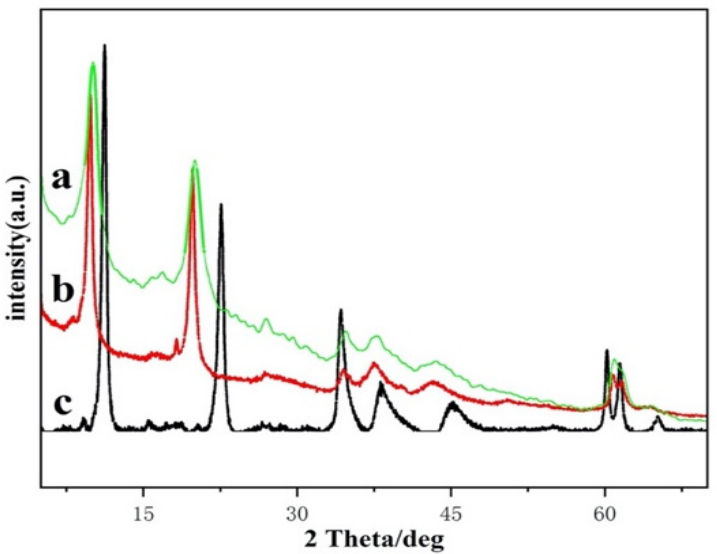

Figure 4. XRD patterns of re- $\mathrm{Mg}_{3} \mathrm{Al}-\mathrm{Pro}-\mathrm{LDHs}(\mathbf{a}), \mathrm{Mg}_{3} \mathrm{Al}-\mathrm{Pro}-\mathrm{LDHs}(\mathbf{b})$, and $\mathrm{Mg}_{3} \mathrm{Al}-\mathrm{LDHs}$ (c).

The metal atoms on the layer of the LDHs material were connected by covalent bonds, and the host layer and the guest were connected by the electrostatic force, the hydrogen bond, and other forces. Previous studies have shown that the long axis length of L-proline is $0.64 \mathrm{~nm}$ and the short axis length is $0.30 \mathrm{~nm}$. According to the data in Table 2, subtracting the thickness of the layer of $0.21 \mathrm{~nm}$ and the hydrogen bond space of $0.27 \mathrm{~nm}[35,36]$, the gallery heights of the intercalated materials were $0.42 \mathrm{~nm}$ and $0.38 \mathrm{~nm}$, respectively. Its value was less than the length of the long axis of the L-proline molecule and greater than the length of its short axis. Therefore, it can be considered that the carboxyl group of L-proline was connected with the metal cations layers and arranged between the layered structures in an inclined manner. The structural model of the intercalation material is shown in Figure 5. Furthermore, the interlayer anions led to the difference of the spacing between the intercalated materials prepared by co-precipitation and rehydration methods. Except for L-proline, the interlayer anion in co-precipitation process was mainly $\mathrm{NO}_{3}{ }^{-}$, while the interlayer anion in the rehydration process was mainly $\mathrm{OH}^{-}$, and the size of $\mathrm{NO}_{3}{ }^{-}$was larger than that of $\mathrm{OH}^{-}$.

Table 2. XRD data of the diffraction peaks of $\mathrm{Mg}_{3} \mathrm{Al}-\mathrm{LDHs}, \mathrm{Mg}_{3} \mathrm{Al}-\mathrm{Pro}-\mathrm{LDHs}$, and re- $\mathrm{Mg}_{3} \mathrm{Al}-\mathrm{Pro}-$ LDHs.

\begin{tabular}{|c|c|c|c|c|c|c|}
\hline & \multicolumn{2}{|c|}{$\mathrm{Mg}_{3} \mathrm{Al}-\mathrm{LDHs}$} & \multicolumn{2}{|c|}{$\mathrm{Mg}_{3} \mathrm{Al}$-Pro-LDHs } & \multicolumn{2}{|c|}{ re-Mg $\mathrm{Ml}_{3} \mathrm{Al}-\mathrm{Pro}-\mathrm{LDHs}$} \\
\hline Diffraction Peaks & $2 \theta\left({ }^{\circ}\right)$ & $\mathrm{d}(\mathrm{nm})$ & $2 \theta\left(^{\circ}\right)$ & $\mathrm{d}(\mathrm{nm})$ & $2 \theta\left({ }^{\circ}\right)$ & $\mathrm{d}(\mathrm{nm})$ \\
\hline 003 & 11.20 & 0.78 & 9.80 & 0.90 & 10.20 & 0.86 \\
\hline 006 & 22.56 & 0.39 & 19.80 & 0.45 & 20.02 & 0.44 \\
\hline 009 & 34.28 & 0.26 & 34.50 & 0.26 & 34.82 & 0.26 \\
\hline 110 & 60.22 & 0.15 & 60.78 & 0.15 & 60.94 & 0.15 \\
\hline
\end{tabular}

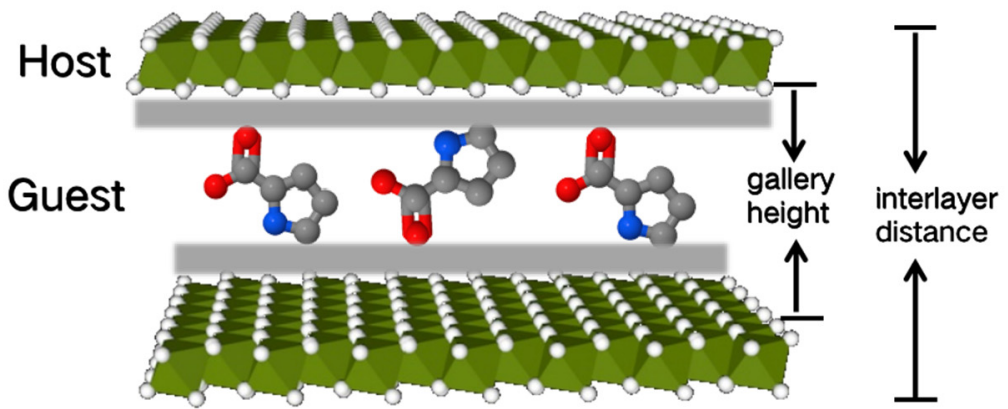

Figure 5. Structural model of L-proline-intercalated LDHs. 


\subsubsection{FTIR}

The successful intercalation of L-proline in magnesium-based LDHs was also confirmed by FTIR. The results are shown in Figure 6. The samples showed a broad absorption peak at $3450 \mathrm{~cm}^{-1}$, which is mainly due to the water molecules between the layers of LDHs and the stretching vibration of hydroxyl groups. The absorption peak moved to a lower wavenumber than the characteristic peak of free hydroxyl (appeared at $3600 \mathrm{~cm}^{-1}$ ), which was caused by the hydrogen bond between the interlayer water molecules and the hydroxyl in the laminate. The characteristic peaks of L-proline samples at $2985 \mathrm{~cm}^{-1}$ and $2742 \mathrm{~cm}^{-1}$ belonged to the asymmetric stretching vibration and bending vibration of the $\mathrm{N}-\mathrm{H}$ bond and the $\mathrm{C}-\mathrm{H}$ bond [37-39]. The $\mathrm{Mg}_{3} \mathrm{Al}-\mathrm{Pro}-\mathrm{LDHs}$ sample also showed the corresponding characteristic peaks, and the peaks were sharp and obvious, but these peaks did not appear in the spectrum of the $\mathrm{Mg}_{3} \mathrm{Al}-\mathrm{LDHs}$ sample, which indicated that the L-proline molecules successfully entered the LDHs interlayer. The characteristic peaks of $\mathrm{Mg}_{3} \mathrm{Al}-\mathrm{Pro}-\mathrm{LDHs}$ samples at $1624 \mathrm{~cm}^{-1}$ and $1384 \mathrm{~cm}^{-1}$ are attributed to the asymmetric bending vibration of the carboxyl group in the L-proline molecule. The above LDHs materials showed obvious characteristic peaks at $827 \mathrm{~cm}^{-1}$ and $677 \mathrm{~cm}^{-1}$, which are mainly attributed to the lattice vibration of the $\mathrm{Mg}-\mathrm{O}$ and $\mathrm{Al}-\mathrm{O}$ bonds and the tensile and flexural vibrations of $\mathrm{M}-\mathrm{O}-\mathrm{M}$ and $\mathrm{O}-\mathrm{M}-\mathrm{O}\left(\mathrm{M}=\mathrm{Mg}^{2+}\right.$ or $\left.\mathrm{Al}^{3+}\right)$, indicating that the layered structure was maintained well [40-42].

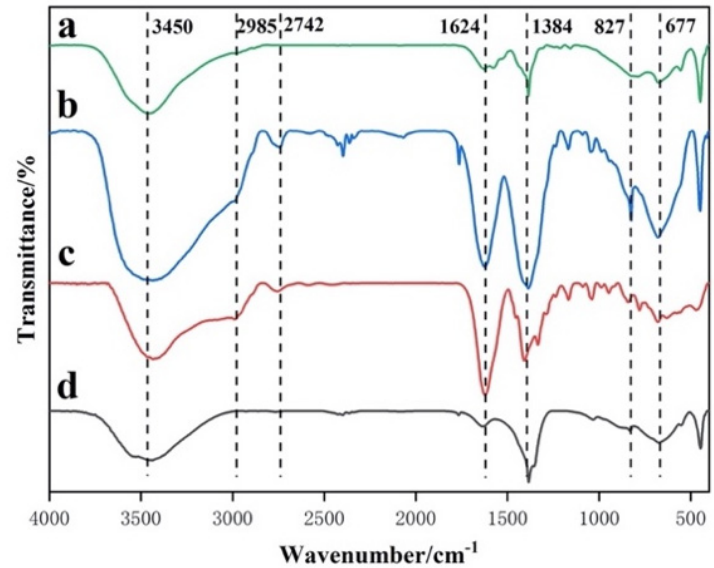

Figure 6. FTIR patterns of re-Mg $\mathrm{Mg}_{3} \mathrm{Al}-\mathrm{Pro}-\mathrm{LDHs}(\mathbf{a}), \mathrm{Mg}_{3} \mathrm{Al}-\mathrm{Pro}-\mathrm{LDHs}(\mathbf{b})$, L-proline (c), and $\mathrm{Mg}_{3} \mathrm{Al}-$ LDHs (d).

\subsubsection{Evaluation of the Catalytic Performance}

It can be seen from Table 3 that the catalytic performance using the L-proline intercalation materials was investigated in the aldol condensation reaction of FA and PA. Compared with re-M $\mathrm{M}_{\mathrm{x}} \mathrm{Al}-\mathrm{LDH}$, the MAL selectivity was greatly improved. Presumably, after the intercalation of L-proline, the active site was replaced or partially replaced with L-proline molecules, allowing the reaction to proceed by the mechanism of the Mannich reaction [43-45]. As shown in Figure 7, under the action of hydrogen ions in the solution, FA and the secondary amine group of L-proline underwent a nucleophilic addition to produce iminium ions, and one molecule of water was released. Then, PA reacted with the iminium ions to form the Mannich base, which later dissociated to MAL. Since the LDHs provided a certain amount of basic sites, other side reactions cannot be completely prohibited. The catalytic performance of the L-proline-intercalated LDHs catalyst synthesized by rehydration was lower than that by co-precipitation. After the calcination of the $\mathrm{Mg}_{3} \mathrm{Al}-\mathrm{LDHs}$ precursor, the structure of the composite metal oxide remained, and the steric hindrance of L-proline molecule was large, which was not conducive to the intercalation assembly of the L-proline group. The density of active sites was lower than that by the co-precipitation method, which led to the reduction of the catalytic activity. 
Table 3. Results of the aldol condensation using LDHs with L-proline intercalation.

\begin{tabular}{ccc}
\hline Catalyst & PA Conversion (\%) & MAL Selectivity (\%) \\
\hline $\mathrm{Mg}_{3} \mathrm{Al}-\mathrm{Pro}-\mathrm{LDHs}$ & 21.09 & 94.58 \\
re-Mg $\mathrm{Ml}-\mathrm{Pro}-\mathrm{LDHs}$ & 19.50 & 64.72 \\
\hline
\end{tabular}

Reaction conditions: $0.2 \mathrm{~g}$ catalyst; $15 \mathrm{~mL}$ DMSO; $3.8 \mathrm{~mL}$ FA; $3.7 \mathrm{~mL} \mathrm{PA} ; 60{ }^{\circ} \mathrm{C} ; 4 \mathrm{~h}$.

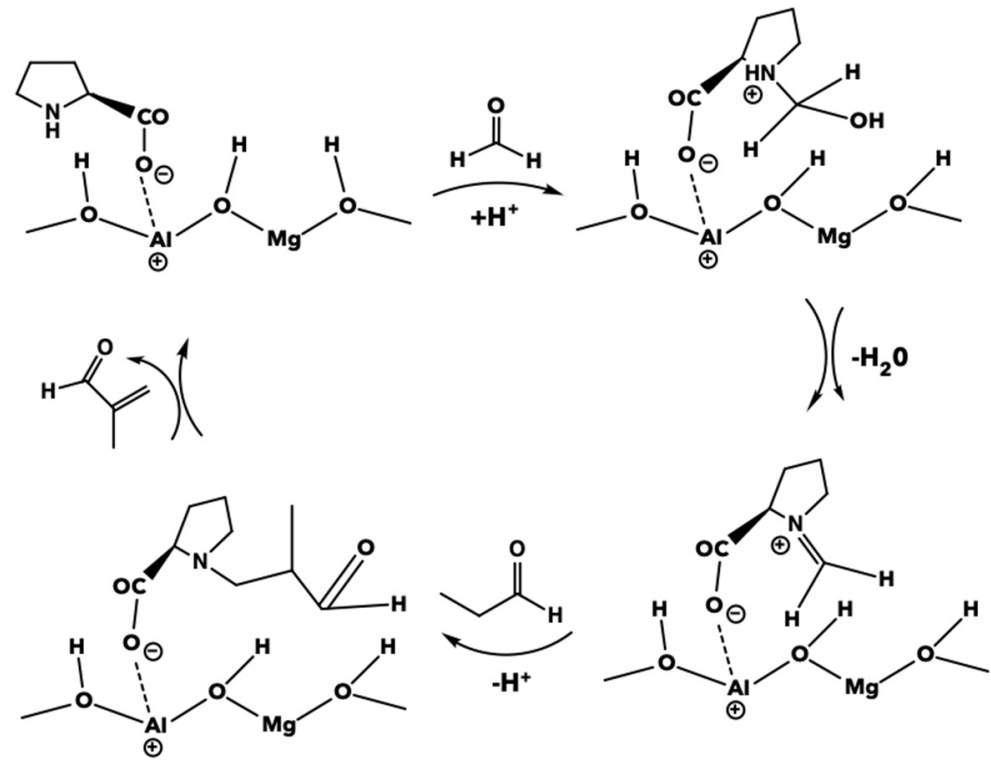

Figure 7. Proposed catalytic cycle for the aldol condensation reaction with the Mannich pathway.

It can be seen from Table 4 that the result of the aldol condensation reaction was closely related to the amount of the substrate. With the increase of the amount of the substrate, the conversion of PA gradually decreased, and the selectivity of MAL increased. In Figure 8, the result indicated that the temperature and the reaction time had impacts on the aldol condensation reaction. Under the optimal operating conditions (substrate amount: 5 mmol; temperature: $60{ }^{\circ} \mathrm{C}$; reaction time: $30 \mathrm{~min}$ ), the PA conversion was $91.39 \%$, and the MAL selectivity was 51.48\%. In Figure 9, the reusability test showed that the MAL selectivity remained unchanged and the catalytic activity decreased after four recycling, which was caused by the leaching of L-proline species and the loss of the catalyst during the separation process. Although L-proline was an effective catalyst for the aldol condensation to produce MAL via the Mannich pathway, the inherent defects (large amount of catalyst, difficult to separate, etc.) led to a challenge for industrial applications. In this work, L-proline was intercalated into LDHs, and the catalytic effect was evaluated in the target reaction. Generally, this catalyst has three advantages as following: (i) facilely and inexpensively synthesizing the catalyst; (ii) making up for the defection of large L-proline consumption; (iii) reducing the cost of product separation. LDHs as a "molecular container" is a fascinating field of research which directly bridges homogenous and heterogeneous catalysis.

Table 4. Results of the aldol condensation reaction with $\mathrm{Mg}_{3} \mathrm{Al}-\mathrm{Pro}-\mathrm{LDH}$ catalysts at different substrate amounts.

\begin{tabular}{ccc}
\hline Substrate Amount (mmol) & PA Conversion (\%) & MAL Selectivity (\%) \\
\hline 5 & 97.67 & 32.97 \\
25 & 41.72 & 45.25 \\
50 & 20.89 & 96.82 \\
\hline
\end{tabular}

Reaction conditions: $0.2 \mathrm{~g}$ catalyst; $15 \mathrm{~mL}$ DMSO; FA:PA molar ratio $=1: 1 ; 60{ }^{\circ} \mathrm{C} ; 4 \mathrm{~h}$. 


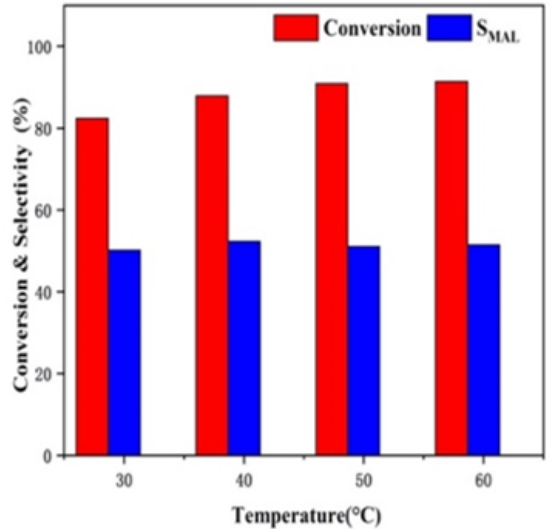

A

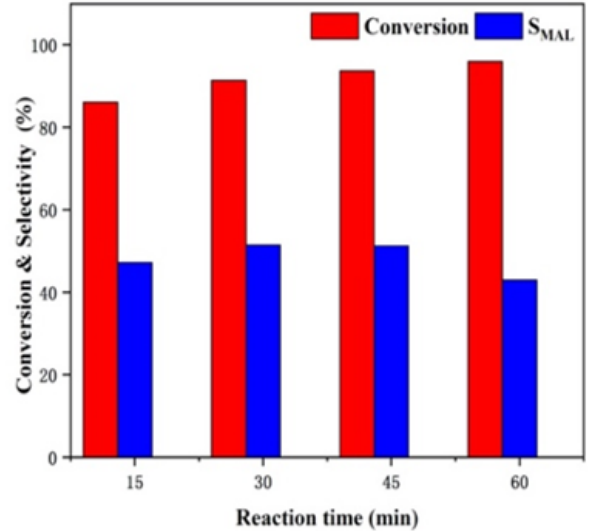

B

Figure 8. Results of the aldol condensation reaction of $\mathrm{Mg}_{3} \mathrm{Al}-\mathrm{Pro}-\mathrm{LDH}$ under different temperatures (A) and different reaction times (B).

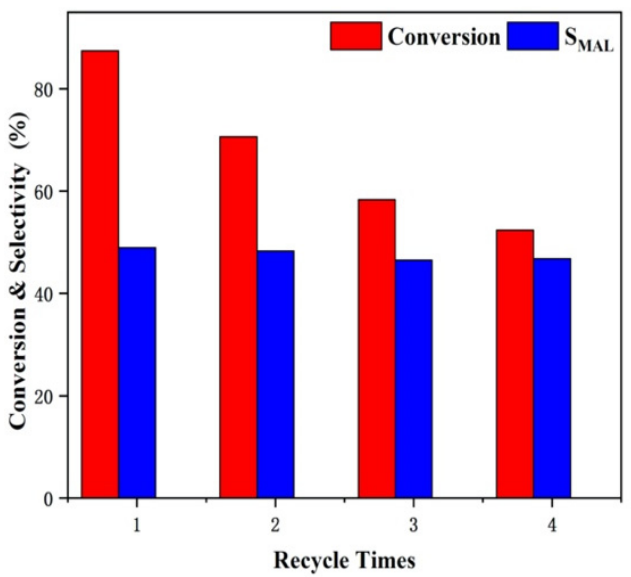

Figure 9. Reusability test results for $\mathrm{Mg}_{3} \mathrm{Al}-\mathrm{Pro}-\mathrm{LDHs}$.

\section{Materials and Methods}

\subsection{Reagents and Instruments}

$\mathrm{Mg}\left(\mathrm{NO}_{3}\right)_{2} \cdot 6 \mathrm{H}_{2} \mathrm{O}$ (99\%; Sinopharm Chemical Reagent Co., Ltd., Beijing, China), $\mathrm{Ca}\left(\mathrm{NO}_{3}\right)_{2} \cdot 4 \mathrm{H}_{2} \mathrm{O}\left(99 \%\right.$; Aladdin Biochemical Technology Co., Shanghai, China), $\mathrm{Al}\left(\mathrm{NO}_{3}\right)_{3} \cdot 9 \mathrm{H}_{2} \mathrm{O}$ (99\%; Xilong Chemical Co., Ltd., Shanghai, China), NaOH (99\%; Tianda Chemical Reagent Factory, Tianjin, China), PA (99\%; Aladdin Biochemical Technology Co., Shanghai, China), FA (37-40\%; Liaoning Quanrui Chemical Reagent Factory, Liaoning, China), ethanol (99.7\%; Tianjin Damao Chemical Reagent Factory, Tianjin, China), MAL (99\%; Aladdin Biochemical Technology Co., Shanghai, China), MP (99\%; Aladdin Biochemical Technology Co., Shanghai, China), BED (99\%, Aladdin Biochemical Technology Co., Shanghai, China), TME (99\%; Aladdin Biochemical Technology Co., Shanghai, China), dimethyl sulfoxide (DMSO; 99\%; Tianjin Fuyu Fine Chemical Co., Ltd., Tianjin, China), L-proline (99\%; Aladdin Biochemical Technology Co., Shanghai, China) were purchased and used without further purification. Decarbonated deionized water was used in all the experimental processes.

XRD patterns were performed at a scanning speed of $10^{\circ} /$ min on a Smart Lab 9 diffractometer equipped with $\mathrm{Cu} \mathrm{K} \alpha$ radiation $(\lambda: 1.5406 \AA$; voltage: $45 \mathrm{kV}$; current: $200 \mathrm{~mA}$ ) in the range of $5-85^{\circ}$ with a step of $0.01^{\circ}$. The XRD data can be used to obtain the information on the crystallinity and layer spacing of the prepared catalyst.

FTIR spectra were obtained using a Bruker EQUINOX55 spectrometer from $400 \mathrm{~cm}^{-1}$ to $4000 \mathrm{~cm}^{-1}$ by the standard $\mathrm{KBr}$ disk method, which was used to determine whether the guest compound entered the interlayer of the LDHs material. 


\subsection{Catalysts Preparation}

Preparation of $\mathrm{M}_{\mathrm{x}} \mathrm{Al}-\mathrm{LDH}$ precursors: $\mathrm{M}_{\mathrm{x}} \mathrm{Al}-\mathrm{LDH}$ precursors with different $\mathrm{M} / \mathrm{Al}$ molar ratios were prepared by the co-precipitation method, and the typical preparation process was as follows. Solution A was mixed solutions of $\mathrm{Ca}\left(\mathrm{NO}_{3}\right)_{2} \cdot 4 \mathrm{H}_{2} \mathrm{O}$ and $\mathrm{Al}\left(\mathrm{NO}_{3}\right)_{3} \cdot 9 \mathrm{H}_{2} \mathrm{O}$ with various $\mathrm{Ca} / \mathrm{Al}$ molar ratios (from 2 to 4 ); solution $\mathrm{B}$ was an aqueous sodium hydroxide solution with $[\mathrm{NaOH}]=1.1 \mathrm{M}$. Then, solutions $\mathrm{A}$ and $\mathrm{B}$ were uniformly poured into a $250 \mathrm{~mL}$ three-neck flask, with a controlled stirring speed of $100 \mathrm{rpm}$ for $6 \mathrm{~h}$. The whole process was carried out in a nitrogen-protected atmosphere. The white emulsion obtained was centrifuged at $3000 \mathrm{rpm}$ for $3 \mathrm{~min}$, washed three times with deionized water and ethanol and dried in an oven at $60^{\circ} \mathrm{C}$ for $24 \mathrm{~h}$ to obtain the Cax Al-LDHs precursor. Meanwhile, different molar ratios of $\mathrm{Mg}_{x} \mathrm{Al}-\mathrm{LDHs}$ precursors were synthesized by the same method using $\mathrm{Mg}\left(\mathrm{NO}_{3}\right)_{2} \cdot 6 \mathrm{H}_{2} \mathrm{O}$ and $\mathrm{Al}\left(\mathrm{NO}_{3}\right)_{3} \cdot 9 \mathrm{H}_{2} \mathrm{O}$. An additional crystallization process was required for the preparation of $\mathrm{Mg}_{\mathrm{x}} \mathrm{Al}-\mathrm{LDHs}$ samples (crystallization temperature: $110^{\circ} \mathrm{C}$; crystallization time: $12 \mathrm{~h}$ ).

Preparation of composite metal oxides: A certain mass of $\mathrm{Mg}_{\mathrm{x}} \mathrm{Al}-\mathrm{LDHs}$ or $\mathrm{Ca}_{\mathrm{x}} \mathrm{Al}-$ LDHs series precursors were fully ground with a quartz mortar and evenly placed in a quartz boat. The precursors were then placed in an atmospheric tube furnace protected by nitrogen and calcined at $450{ }^{\circ} \mathrm{C}$ for $4 \mathrm{~h}$. The product was naturally cooled to room temperature, namely $\mathrm{Ca}_{x} \mathrm{Al}-\mathrm{MMOs}$ or $\mathrm{Mg}_{x} \mathrm{Al}-\mathrm{MMOs}$.

Preparation of re-M $\mathrm{M}_{x} \mathrm{Al}-\mathrm{LDH}$ s: A certain mass of $\mathrm{Ca}_{x} \mathrm{Al}-\mathrm{MMOs}$ or $\mathrm{Mg}_{\mathrm{x}} \mathrm{Al}-\mathrm{MMOs}$ was placed in a three-neck flask and protected by nitrogen. An aqueous sodium hydroxide solution with $[\mathrm{NaOH}]=1.1 \mathrm{M}$ was added to the flask and stirred at $30^{\circ} \mathrm{C}$ for $2 \mathrm{~h}$, then centrifuged and separated. The obtained product was washed three times with deionized water and ethanol and placed in a vacuum-drying oven for $24 \mathrm{~h}$ to obtain a structurally restored solid base catalyst, namely re-Mg $\mathrm{Ml}-\mathrm{LDH}$ or re-Cax $\mathrm{Al}-\mathrm{LDHs}$.

Preparation of $\mathrm{Mg}_{3} \mathrm{Al}-\mathrm{Pro}-\mathrm{LDH}$ : The L-proline-intercalated LDHs catalyst was prepared by the co-precipitation method. Firstly, $100 \mathrm{~mL}$ of solutions $\mathrm{A}$ and $\mathrm{B}$ were prepared. Solution A was mixed solutions of $\mathrm{Ca}\left(\mathrm{NO}_{3}\right)_{2} \cdot 4 \mathrm{H}_{2} \mathrm{O}(0.6 \mathrm{M})$ and $\mathrm{Al}\left(\mathrm{NO}_{3}\right)_{3} \cdot 9 \mathrm{H}_{2} \mathrm{O}(0.2 \mathrm{M})$; solution $\mathrm{B}$ was a mixed solution of $\mathrm{L}$-proline and $\mathrm{NaOH}$ with an equal concentration $(1.1 \mathrm{M})$. Solutions A and B were diverted into a $250 \mathrm{~mL}$ three-neck flask and reacted for $6 \mathrm{~h}$ at room temperature. All the above processes were carried out under nitrogen protection. The slurry obtained was washed three times with deionized water and then placed in a vacuum-drying oven for $24 \mathrm{~h}$, namely $\mathrm{Mg}_{3} \mathrm{Al}$-Pro-LDHs.

Preparation of re- $\mathrm{Mg}_{3} \mathrm{Al}-\mathrm{Pro}-\mathrm{LDHs}$ : The preparation method is similar to that used to prepare the re- $\mathrm{M}_{\mathrm{x}} \mathrm{Al}-\mathrm{LDHs}$ catalysts. L-proline was dissolved in a newly prepared $\mathrm{NaOH}$ solution with an equal concentration $(0.06 \mathrm{M})$ and mixed with a certain mass of composite metal oxides, and the resulting slurry was reacted at room temperature for $24 \mathrm{~h}$. All the above processes were carried out under nitrogen protection. The product was fully washed until it was approximately neutral and placed in a vacuum-drying oven for $24 \mathrm{~h}$, namely re-Mg $\mathrm{Mg}_{3} \mathrm{Al}-\mathrm{Pro}-\mathrm{LDHs}$.

\subsection{Synthesis of MAL from $F A$ and $P A$}

The FA and PA condensation reaction was carried out in a $100 \mathrm{~mL}$ stainless steel reactor. The solid-phase catalyst was mixed with a solvent (DMSO) and added into the reactor. FA, PA, and internal standard ethanol were added sequentially, and the reaction began. After the reaction, the liquid-phase products were separated by centrifugation and analyzed by gas chromatography.

The catalytic performances of the catalysts were evaluated based on the conversion of PA and the selectivity of MAL. The corresponding expressions are as follows.

The conversion of PA was written as:

$$
X_{P A}=\frac{n_{P A, \text { in }}-n_{P A, \text { out }}}{n_{P A, \text { in }}} \times 100 \%,
$$


The selectivity of MAL was written as:

$$
S_{M A L}=\frac{n_{M A L, \text { out }}}{n_{P A, \text { in }}-n_{P A, \text { out }}} \times 100 \%,
$$

The selectivity of MP was written as:

$$
S_{M P}=\frac{n_{M P, \text { out }}}{n_{P A, \text { in }}-n_{P A, \text { out }}} \times 100 \%,
$$

The selectivity of BED was written as:

$$
S_{B E D}=\frac{n_{B E D, \text { out }}}{n_{P A, \text { in }}-n_{P A, \text { out }}} \times 100 \%,
$$

The selectivity of TME was written as:

$$
S_{T M E}=\frac{n_{T M E, o u t}}{n_{P A, \text { in }}-n_{P A, \text { out }}} \times 100 \%,
$$

where $n_{P A, \text { in }}$ and $n_{P A, \text { out }}$ are the moles of PA in the system before and after the reaction, respectively, and $n_{M A L, o u t}, n_{M P, o u t}, n_{B E D, o u t}$, and $n_{T M E, \text { out }}$ are the obtained moles of MAL, $\mathrm{MP}, \mathrm{BED}$, and TME.

\section{Conclusions}

Due to the defects of homogeneous catalysts and difficult separation, it is urgent to develop heterogeneous catalysts with excellent catalytic performance in the aldol condensation reaction of FA and PA. In this paper, based on its so-called memory effect, the interlayer anion in LDHs was successfully replaced by $\mathrm{OH}^{-}$after calcination and rehydration processes. The rehydrated LDHs as unselective solid-base catalysts presented high catalytic activity and low MAL selectivity. Then, L-proline was successfully intercalated and assembled in LDHs, which was confirmed by XRD and FTIR. The latter showed higher MAL selectivity. The reusability test showed that the selectivity of the target product remained unchanged after the catalyst was recycled four times. The leaching of L-proline species into the solution and the loss of the catalyst during the separation process resulted in a gradual decrease in the catalytic activity. This work provides a facile and cost-effective approach to the preparation of L-proline-intercalated LDHs, which can be used as a heterogeneous catalyst in the green catalysis of aldol condensation reactions.

Author Contributions: Data curation, L.J. and G.L.; Investigation, L.J., G.L. and H.L.; Methodology, L.J. and G.L.; Software, L.J.; Supervision, G.L.; Validation, L.J.; Writing—original draft, L.J.; Writing一 review \& editing, G.L. All authors have read and agreed to the published version of the manuscript.

Funding: This research received no external funding.

Acknowledgments: The authors acknowledge the financial support from Sanlibennuo Chemical Industry Co., Weifang, China.

Conflicts of Interest: The authors declare no conflict of interest.

\section{References}

1. Diao, Y.; Yang, P.; Yan, R.; Jiang, L.; Wang, L.; Zhang, H.; Li, C.; Li, Z.; Zhang, S. Deactivation and regeneration of the supported bimetallic Pd-Pb catalyst in direct oxidative esterification of methacrolein with methanol. Appl. Catal. B Environ. 2013, 142, 329-336. [CrossRef]

2. Jaber, D.; Jean-Luc, D.; Fabrizio, C.; Rostamizadeh, M.; Patience, G.S. Catalysis for the synthesis of methacrylic acid and methyl methacrylate. Chem. Soc. Rev. 2018, 47, 7703-7738.

3. Fan, L.; Xu, B.; Li, J.; Yan, R.; Diao, Y.; Li, C. Kinetic studies on both synthesis of methacrolein catalyzed by an ionic liquid and catalyst deactivation. Ind. Eng. Chem. Res. 2021, 60, 5411-5420. [CrossRef]

4. Yan, R.; Li, Z.; Diao, Y.; Fu, C.; Wang, H.; Li, C.; Chen, Q.; Zhang, X.; Zhang, S. Green process for methacrolein separation with ionic liquids in the production of methyl methacrylate. Aiche J. 2011, 57, 2388-2396. [CrossRef] 
5. Li, Y.C.; Yan, R.Y.; Wang, L.; Liu, L.; Liu, D.; Zhang, H.; Diao, Y.Y.; Li, Z.X.; Zhang, S.J. Synthesis of methacrolein by condensation of propionaldehyde with formaldehyde. Adv. Mater. Res. 2012, 396-398, 1094-1097. [CrossRef]

6. West, R.M.; Liu, Z.Y.; Peter, M.; Gärtner, C.A.; Dumesic, J.A. Carbon-Carbon bond formation for biomass-derived furfurals and ketones by aldol condensation in a biphasic system. Mol. Catal. 2008, 296, 18-27. [CrossRef]

7. Vashishtha, M.; Mishra, M.; Shah, D.O. A novel approach for selective cross aldol condensation using reusable NaOH-cationic micellar systems. Appl. Catal. A Gen. 2013, 466, 38-44. [CrossRef]

8. Li, Y.; Zheng, Y.; Wang, L.; Fu, Z. Oxidative esterification of methacrolein to methyl methacrylate over supported gold catalysts prepared by colloid deposition. Chemcatchem 2017, 11, 1960-1968. [CrossRef]

9. Liu, Y.; Wu, Q.; Yin, D.; Li, D. Latest progress and application of Mannich reaction. Chin. J. Org. Chem. 2016, 36, 927-938. [CrossRef]

10. de María, P.D.; Bracco, P.; Castelhano, L.F.; Bargeman, G. Influence of the organocatalyst in the Aldol/Mannich-Type product selectivities in $\mathrm{C}-\mathrm{C}$ bond forming reactions. ACS Catal. 2011, 1, 70-75. [CrossRef]

11. Lei, L.; Tao, R.; Shi, J.; Jing, X.; Ma, H. Rapid and continuous synthesis of methacrolein with high selectivity by condensation of propanal with formaldehyde in laboratory. Can. J. Chem. Eng. 2017, 95, 1985-1992. [CrossRef]

12. Yu, J.; Jensen, A.D.; Wang, L.; Li, C.; Zhang, S. Catalytic synthesis of methacrolein via the condensation of formaldehyde and propionaldehyde with L-proline. Green Chem. 2020, 22, 4222-4230. [CrossRef]

13. Elmekawy, A.A.; Sweeney, J.B.; Brown, D.R. Efficient synthesis of supported proline catalysts for asymmetric aldol reactions Catal. Sci. Technol. 2015, 5, 690-696. [CrossRef]

14. Feng, X.; Jena, H.S.; Leus, K.; Wang, G.; Ouwehand, J.; Van Der Voort, P. L-proline modulated zirconium metal organic frameworks: Simple chiral catalysts for the aldol addition reaction. J. Catal. 2018, 365, 36-42. [CrossRef]

15. An, Z.; Zhang, W.; Shi, H.; He, J. An effective heterogeneous L-proline catalyst for the asymmetric aldol reaction using anionic clays as intercalated support. J. Catal. 2006, 241, 319-327. [CrossRef]

16. Heravi, M.M.; Mohammadi, P. Layered double hydroxides as heterogeneous catalyst systems in the cross-coupling reactions: An overview. Mol. Divers. 2021, 11, 1-19. [CrossRef]

17. Wang, Y.; Wang, S.; Li, X.; Bai, P.; Yan, W.; Yu, J. Layered inorganic cationic frameworks beyond layered double hydroxides: Structures and applications. Eur. J. Inorg. Chem. 2020, 43, 4055-4063. [CrossRef]

18. Yang, R.; Zhou, Y.; Xing, Y.; Li, D.; Jiang, D.; Chen, M.; Shi, W.; Yuan, S. Synergistic coupling of CoFe-LDH arrays with NiFe-LDH nanosheet for highly efficient overall water splitting in alkaline media. Appl. Catal. B Environ. 2019, 253, 131-139. [CrossRef]

19. Wang, N.; Huang, Z.; Li, X.; Li, J.; Ji, S.; An, Q.-F. Tuning molecular sieving channels of layered double hydroxides membrane with direct intercalation of amino acids. J. Mater. Chem. A 2018, 6, 17148-17155. [CrossRef]

20. Zhang, X.; Yan, L.; Li, J.; Yu, H. Adsorption of heavy metals by L-cysteine intercalated layered double hydroxide: Kinetic, isothermal and mechanistic studies. J. Colloid Interface Sci. 2020, 562, 149-158. [CrossRef]

21. Mallakpour, S.; Hatami, M. An effective, low-cost and recyclable bio-adsorbent having amino acid intercalated LDH@Fe3O4/PVA magnetic nanocomposites for removal of methyl orange from aqueous solution. Appl. Clay Sci. 2019, 15, 127-137. [CrossRef]

22. Rives, V.; Arco, M.D.; Martín, C. Intercalation of drugs in layered double hydroxides and their controlled release: A review. Appl. Clay Sci. 2013, 88, 239-269. [CrossRef]

23. Bukhtiyarova, M.V. A review on effect of synthesis conditions on the formation of layered double hydroxides. J. Solid State Chem. 2019, 269, 494-506. [CrossRef]

24. Gaskell, E.E.; Ha, T.; Hamilton, A.R. Ibuprofen intercalation and release from different layered double hydroxides. Ther. Deliv. 2018, 9, 653-666. [CrossRef] [PubMed]

25. Varga, G.; Kónya, Z.; Kukovecz, Á.; Sipos, P.; Pálinkó, I. Co(II)-amino acid-CaAl-layered double hydroxide composites construction and characterization. J. Mol. Struct. 2019, 1179, 263-268. [CrossRef]

26. Deng, X.; Huang, J.; Wan, H.; Chen, F.; Lin, Y.; Xu, X.; Ma, R.; Sasaki, T. Application progress of functionalized layered double hydroxides. J. Mater. Sci. Eng. 2019, 37, 509-516.

27. Huo, Y.S.; Zhu, L.H.; Yang, J.; Sun, Y.L. Structure, Properties and preparation of layered double hydroxides and its application in field of catalysis. Bull. Chin. Ceram. Soc. 2013, 21, 429-433.

28. Deng, X.; Huang, J.; Wan, H.; Chen, F.; Lin, Y.; Xu, X.; Ma, R.; Sasaki, T. Recent progress in functionalized layered double hydroxides and their application in efficient electrocatalytic water oxidation. J. Energy Chem. 2018, 32, 93-104. [CrossRef]

29. Prevot, V.; Bourgeat-Lami, E. Recent advances in layered double hydroxide/polymer latex nanocomposites: From assembly to in situ formation. Layer. Double Hydroxide Polym. Nanocompos. 2020, 461-495. [CrossRef]

30. Vijaikumar, S.; Dhakshinamoorthy, A.; Pitchumani, K. L-proline anchored hydrotalcite clays: An efficient catalyst for asymmetric Michael addition. Appl. Catal. A Gen. 2008, 340, 25-32. [CrossRef]

31. Chen, S.; Ma, J.; Zhang, T.; Zhang, S.; Zhang, C.; Cheng, H.; Ge, Y.; Liu, L.; Tong, Z.; Zhang, B. Intercalated cobalt porphyrin between layered double hydroxide nanosheets as an efficient and recyclable catalyst for aerobic epoxidation of alkenes. Appl. Clay Sci. 2020, 187, 105478.

32. Meili, L.; Lins, P.V.; Zanta, C.L.P.S.; Soletti, J.I.; Ribeiro, L.M.O.; Dornelas, C.B.; Silva, T.L.; Vieira, M.G.A. MgAl-LDH/Biochar composites for methylene blue removal by adsorption. Appl. Clay Sci. 2019, 168, 11-20. [CrossRef]

33. Demir, F.; Demir, B.; Yalcinkaya, E.E.; Cevik, S.; Demirkol, D.O.; Anik, U.; Timur, S. Amino acid intercalated montmorillonite: Electrochemical biosensing applications. RSC Adv. 2014, 4, 50107-50113. [CrossRef] 
34. Stamate, A.E.; Pavel, O.D.; Zavoianu, R.; Marcu, I.C. Highlights on the catalytic properties of polyoxometalate-intercalated layered double hydroxides: A review. Catalysts 2020, 10, 57. [CrossRef]

35. He, S.; An, Z.; Wei, M.; Evans, D.G.; Duan, X. Layered double hydroxide-based catalysts: Nanostructure design and catalytic performance. Chem. Commun. 2013, 49, 5912-5920. [CrossRef]

36. Ma, X.; Zheng, J.; Pang, H. Intercalation of Mg-Al layered double hydroxides by L-proline: Synthesis and characterization. Res. Chem. Intermed. 2012, 38, 629-638. [CrossRef]

37. Fudala, Á.; Pálinkó, I.; Kiricsi, I. Preparation and characterization of hybrid organic-inorganic composite materials using the amphoteric property of amino acids: Amino acid intercalated layered double hydroxide and montmorillonite. Inorg. Chem. 1999, 38, 46-53. [CrossRef] [PubMed]

38. Subramanian, T.; Dhakshinamoorthy, A.; Pitchumani, K. Amino acid intercalated layered double hydroxide catalyzed chemoselective methylation of phenols and thiophenols with dimethyl carbonate. Cheminform 2013, 54, 7167-7170.

39. Wang, G.; Li, Z.; Fan, L.; Li, C.; Zhang, S. Sec-amine grafted D301 resin catalyzed fixed-bed process for continuous preparation of methacrolein via Mannich reaction. Chem. Eng. J. 2019, 370, 625-636. [CrossRef]

40. Bing, W.; Zheng, L.; He, S.; Rao, D.; Xu, M.; Zheng, L.; Wang, B.; Wang, Y.; Wei, M. Insights on active sites of CaAl-hydrotalcite as a high-performance solid base catalyst toward aldol condensation. ACS Catal. 2017, 8, 656-664. [CrossRef]

41. Bing, W.; Wang, H.; Zheng, L.; Rao, D.; Yang, Y.; Zheng, L.; Wang, B.; Wang, Y.; Wei, M. CaMnAl-hydrotalcite solid basic catalyst toward aldol condensation reaction with a comparable level to liquid alkali catalysts. Green Chem. 2018, 20, 3071-3080. [CrossRef]

42. Zhang, G.; Wu, L.; Tang, A.; Weng, B.; Atrens, A.; Ma, S.; Liu, L.; Pan, F. Sealing of anodized magnesium alloy AZ31 with MgAl layered double hydroxides layers. RSC Adv. 2018, 8, 2248-2259. [CrossRef]

43. Trost, B.M.; Hung, C.I.; Gnanamani, E. Tuning the reactivity of ketones through unsaturation: Construction of cyclic and acyclic quaternary stereocenters via Zn-ProPhenol catalyzed mannich reactions. ACS Catal. 2019, 9, 1549-1557. [CrossRef]

44. An, Y.-J.; Wang, C.-C.; Liu, Z.-P.; Tao, J.-C. Isosteviol proline conjugates as highly efficient amphiphilic organocatalysts for asymmetric three-component Mannich reactions in the presence of water. Helv. Chim. Acta 2012, 95, 43-51. [CrossRef]

45. Arya, K.; Rajesh, U.C.; Rawat, D.S. Proline confined FAU zeolite: Novel hybrid catalyst for synthesis of spiro heterocycles via mannich type reaction. Green Chem. 2012, 14, 3344-3351. [CrossRef] 